http://dx.doi.org/10.4314/ajtcam.v10i4.12

\title{
EFFECTS OF GAN LIAN YU PING FENG POWDER ON THE ANTIBODY TITERS TO INFECTIOUS LARYNGOTRACHEITIS VACCINE AND SOME NONSPECIFIC IMMUNE INDEXES IN CHICKENS
}

\author{
Kong Chunmei, ${ }^{1,2}$ Zhao Zhujun, ${ }^{1}$ Zhong Xiuhui, ${ }^{1,3^{*}}$ \\ ${ }^{1}$ College of Veterinary Medicine, Agricultural University of Hebei, Baoding, 071001, P. R. China \\ ${ }^{2}$ Baoding Vocational College of Technology, Baoding 071000, China, ${ }^{3}$ Institute of Traditional Chinese \\ Veterinary Medicine, Agricultural University of Hebei, Baoding 071001, China

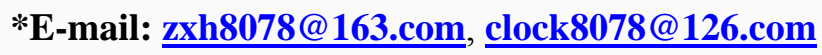

\begin{abstract}
The study was conducted in order to investigate the immuno-enhancing property of the Chinese herbal formula, Gan lian Yu ping feng powder. Three hundred and thirty six 45-day-old chicks were randomly divided into eight groups. The chicks in groups A, B, C were orally given $0.25 \mathrm{~g} / \mathrm{mL}$ (low-), $0.5 \mathrm{~g} / \mathrm{mL}$ (middle-) and $1.0 \mathrm{~g} / \mathrm{mL}$ (high) dose of Gan lian Yu ping feng powder in the drinking water respectively for 3 days consecutively. They were then immunised with infectious laryngotracheitis vaccine (ILTV) on the 4th day. Groups D, E, F were given $0.25 \mathrm{~g} / \mathrm{mL}, 0.5 \mathrm{~g} / \mathrm{mL}$ and $1.0 \mathrm{~g} / \mathrm{mL}$ dose of Gan lian Yu ping feng powder respectively after the immunisation for three days consecutively. Group G was Wen du qing (a government approved herbal product for ILT) control group, and group $\mathbf{H}$ was blank control group. At 52, 59, 73, 87 days of age, 8 chicks of each group were selected randomly for blood sampling to determine the levels of IFN- $\gamma$, IL-4 and the antibody of ILT. Then the chickens were sacrificed, with the thymus, spleen and Bursa of Fabricius being weighed for the calculation of immune organ indexes. The results showed that high and middle dosages of Gan lian Yu ping feng powder given at the day before immunisation and 3 days after immunisation elevated not only the contents of IFN- $\gamma$, the antibody titers of ILT $(\mathrm{P}<0.01)$ and the immune organ indexes $(\mathrm{P}<0.05)$ significantly, but also reduced the contents of IL-4. There was a significantly different degree of enhancement in the content of IFN- $\gamma$, the antibody of ILT $(\mathrm{P}<0.01)$ and the immune organ index $(\mathrm{P}<0.05)$. The results indicate that Gan lian Yu ping feng powder effectively improves the immunity in chickens.
\end{abstract}

Key words: Gan lian Yu ping feng powder; chicken; Infectious Laryngotracheitis vaccine; immune function

\section{Introduction}

With the fast growing poultry farming industry, infectious diseases break out more often than ever before (Ren et al., 2007). Vaccination in controlling the infectious diseases is often applied and usually effective. However, there have been increasing failure reports with vaccination because of changing strains of the pathogenic organisms (Ren et al., 2007; Cheng et al., 2011), short duration of antibody existence, as well as poor cellular immunity (Sun et al., 2006). Therefore, it is of great importance to study the potential for herbals as immunomodulators to enhance the innate immunity and defense functions of animals and birds. Immunological principles and methodology have been applied in the field of herbal research, especially of the tonic herbs which are documented in the ancient book to be able to replenish the vital energy and to nourish Qi (Wang et al,2008; Malik et al, 2009). Qi is believed to be a disease-resistant force in traditional Chinese medicine (TCM), somewhat like immunity. Lots of studies have demonstrated that Chinese herbal medicines possess immuno-enhancing properties (Xu et al., 2010; Xu et al.,2011; Wang et al, 2012) and are playing a novel role in preventing and controlling various diseases of domestic animals and fowls, including infectious diseases (Zhang et al., 2012; Cheng et al., 2011). Applying herbals in animal production and disease controlling has become a research focus in veterinary practice (Liu et al, 
http://dx.doi.org/10.4314/ajtcam.v10i4.12

2011).

Yu ping feng San (Jade-screen powder) is a traditional replenishing formula documented in Shi Yi De Xiao Fang, an ancient TCM textbook, and is composed of huang qi (Radix Astragali), bai zhu (Rhizoma Atractylodis Macrocephalae) and fang feng (Radix Saposhnikoviae). This composed formula possesses Qi nourishing and defence system strengthening properties. The formula has been used for thousands of years clinically for influenza, infection in the respiratory tract, bronchial asthma, etc. (Poon et al., 2006). Though there are reports on immuno-enhancing effects of herbals in humans and other mammals (Poon et al, 2006; Tang and Jiang, 2011; Wang et al, 2012), there have been few reports on the herbal immuno-modulating effect on poultry (Wang et al, 2006).

Our present study was conducted to evaluate the effects of Gan lian Yu ping feng powder on cyto-immunological and humeral immunity of chicks with the aim of providing references to developing high quality and low side effects immuno-enhancers for clinical usage, using a vaccination model of infectious laryngotracheitis and analysing the antibody titers, indexes of immunological organs and cytokine contents such as IFN- $\gamma$ and IL-4.

\section{Materials and methods}

Experimental animals

336 healthy Jingbai (Beijing white) day-old chicks were adopted as experimental animals supplied by a local poultry farm in Baoding city. The birds were fed and watered conventionally.

\section{Herbal formula}

\section{Preparation of herbal decoction}

By comparing the immuno-enhancing properties of three different herbal formulas, we selected the Gan lian Yu ping feng powder as the herbal formula after pretrial studies. The herbal formula contain huang qi (Radix Astragali) 3 parts, bai zhu (Rhizoma atractylodis macrocephalae) 2 parts, fang feng (Radix saposhnikoviae) 2 parts, chuan xin lian (Herba andrographis) 2 parts, and gan cao (Radix glycyrrhizae) 1 part. All the five herbs were purchased from Tong Ren Tang Herbal Pharmacy (Beijing,China) and authenticated.

\section{Reagents}

Chicken infectious laryngotrachitis vaccine, frozen dried, was supplied by Hayao Group Biological Vaccine Company Ltd., Lot Number 201101. Wen du qing, a commercially available herbal product, contains yin yang huo (Epimedium) 62.5 g, huang qi (Radix Astragali) 62.5 g, produced by Hunan Xiangda Veterinary Drug Company Ltd. Lot number (2007) 180246203. ILT antibody, IL-4 and IFN- $\gamma$ ELISA kits were purchased from R\&B Company, USA.

\section{Preparation of herbal decoction}

The herbs, huang qi (Radix Astragali), bai zhu (Rhizoma Atractylodis macrocephalae) and fang feng (Raidix saposhnikoviae), chuan xin lian (Herba andrographis), gan cao (Radix Glycyrrhizae), were used in the following proportion:

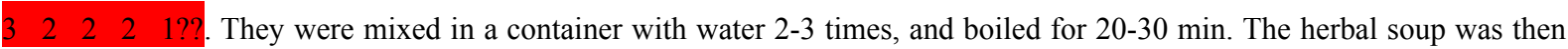
filtered with 8 folds gauze and the soup was collected. The above procedure was repeated twice. The three decoctions were combined and simmered to the desired volume, that is, $1 \mathrm{ml}$ herbal soup contains $1 \mathrm{~g}$ of raw herb. The soup was Stored at $4^{\circ} \mathrm{C}$ for use after sterilisation. The soup was thereafter diluted to the desired volume when used.

\section{Animal grouping and treatment}


http://dx.doi.org/10.4314/ajtcam.v10i4.12

The 336 chicks were fed until 45 days of age and then divided into 8 groups of 32 birds each. Chicks in groups A, B, C were given free drinking water containing $0.25 \mathrm{~g} / \mathrm{ml}$ (low-dose), $0.5 \mathrm{~g} / \mathrm{ml}$ (middle-dose), $1.0 \mathrm{~g} / \mathrm{ml}$ (high-dose) of herbal soup of Gan lian Yu ping feng powder for 3 days, respectively. They were then immunised with frozen-dried ILT vaccine on the 4th day. Birds in groups D, E and F were given free drinking water containing $0.25 \mathrm{~g} / \mathrm{ml}$ (low-dose), $0.5 \mathrm{~g} / \mathrm{ml}$ (middle-dose), $1.0 \mathrm{~g} / \mathrm{ml}$ (high-dose) of herbal soup of Gan lian Yu ping feng powder for 3 days, respectively, starting on the 3rd day post immunisation with frozen-dried ILT vaccine. Group G received wen du qing, a reference herbal formula documented in the Chinese Pharmacopoeia as the positive drug control group. The drug was given according to the manufacturer's instructions $(0.0004 \mathrm{~g} / \mathrm{ml})$. Group $\mathrm{H}$ was the immunisation control group, birds in this group only were immunised without herbal treatment.

\section{Measurement of ILT antibody titers}

The measurement of ILT antibody titers was carried out on the age of days 52, 59, 73, and 87. Eight birds were selected in each group and blood samples were collected by puncturing the wing vein. Serum was separated for ELISA analysis of antibody titers and cytokines IFN- $\gamma$ and IL-4 were measured according to the manufacturer's instructions. The selected birds were sacrificed after blood sampling to measure the organ indexes, such as thymus, spleen, Bursa of Fabricius. All procedures concerning animal treatments and experimentations in this study were reviewed and approved by the Institutional Committee for Ethical Use of Experimental Animals at Hebei Provincial Department of Animal Science. The organ index was calculated using the formula:

Organ index= organ weight $(\mathrm{mg}) /$ body weight $(\mathrm{g})$.

\section{Statistical analysis}

All statistics were conducted using SPSS 17.0 software. Data were expressed as Mean \pm SD. One-way ANOVA was applied to compare the difference. AP-value of less than 0.05 was considered significant, and P less than 0.01 was considered highly significant.

\section{Results}

Changes of antibody titers

The antibody titers of all the herbal treated groups were significantly higher than the control group at the three time point. The $\mathrm{P}$ value was less than 0.01 at 59, 73, 87 days of age when comparison was made between the high-, middle-dose herbal groups and the control group or wen du qing drug control group. The P value was less than 0.05 at 73,87 days of age between the low dose group and the controls (Table 1). The results strongly suggest that the herbal formula has a positive impact on the antibody production of the birds.

\section{Effect of herbals on immunological organ index in chickens}

During the whole period of the trial, the immunological organs such as thymus, spleen, Bursa of Fabricius of the chicks showed no visible pathological changes. The thymus index was significantly higher in the high- and middle-dose groups compared with the control group, whether the herbals were given pre- or post vaccination, the $\mathrm{P}$ value being $<0.01$ at day 73 , day 87 of age, $\mathrm{P}<0.05$ at day 52 and day 59 of age. Significant changes were achieved at day 59, day 73, and day 87 of age in the low-dose group $(\mathrm{P}<0.05)$, and at day 52, and day 59 in the wen du qing group. There was no significant difference between Gan lian Yu ping feng groups and the positive drug control group (Table 2). 
http://dx.doi.org/10.4314/ajtcam.v10i4.12

Table 1: ILT antibody titers in different experimental groups $(\log 2)$

\begin{tabular}{llccc}
\hline \multirow{2}{*}{ Groups } & \multicolumn{4}{c}{ Age (day) } \\
\cline { 2 - 5 } & 52 & 59 & 73 & 87 \\
\hline A & $4.56 \pm 0.008^{\mathrm{a}}$ & $4.96 \pm 0.004^{\mathrm{a}}$ & $5.36 \pm 0.008^{\mathrm{a}}$ & $5.34 \pm 0.009^{\mathrm{a}}$ \\
$\mathrm{B}$ & $4.67 \pm 0.012^{\mathrm{b}}$ & $4.99 \pm 0.018^{\mathrm{a}}$ & $5.37 \pm 0.012^{\mathrm{a}}$ & $5.36 \pm 0.015^{\mathrm{a}}$ \\
$\mathrm{C}$ & $4.86 \pm 0.057^{\mathrm{B}}$ & $5.19 \pm 0.008^{\mathrm{C}}$ & $5.55 \pm 0.001^{\mathrm{C}}$ & $5.67 \pm 0.019^{\mathrm{C}}$ \\
$\mathrm{D}$ & $4.81 \pm 0.012^{\mathrm{B}}$ & $5.12 \pm 0.017^{\mathrm{B}}$ & $547 \pm 0.031^{\mathrm{B}}$ & $5.56 \pm 0.001^{\mathrm{B}}$ \\
$\mathrm{E}$ & $4.69 \pm 0.019^{\mathrm{b}}$ & $5.06 \pm 0.010^{\mathrm{b}}$ & $5.39 \pm 0.008^{\mathrm{b}}$ & $5.44 \pm 0.025^{\mathrm{b}}$ \\
$\mathrm{F}$ & $4.85 \pm 0.015^{\mathrm{B}}$ & $5.18 \pm 0.006^{\mathrm{C}}$ & $5.56 \pm 0.006^{\mathrm{C}}$ & $5.65 \pm 0.017^{\mathrm{C}}$ \\
$\mathrm{G}$ & $4.75 \pm 0.001^{\mathrm{b}}$ & $5.13 \pm 0.006^{\mathrm{B}}$ & $5.49 \pm 0.003^{\mathrm{B}}$ & $5.55 \pm 0.006^{\mathrm{B}}$ \\
$\mathrm{H}$ & $4.67 \pm 0.007^{\mathrm{b}}$ & $4.98 \pm 0.009^{\mathrm{b}}$ & $5.39 \pm 0.002^{\mathrm{b}}$ & $5.45 \pm 0.017^{\mathrm{b}}$ \\
\hline
\end{tabular}

Notes: 1. Groups A, B, C were given $0.25 \mathrm{~g} / \mathrm{ml}, 0.5 \mathrm{~g} / \mathrm{ml}, 1.0 \mathrm{~g} / \mathrm{ml}$ of herbal soup respectively, 1 day before vaccination. Groups D, E, F were given $0.25 \mathrm{~g} / \mathrm{ml}, 0.5 \mathrm{~g} / \mathrm{ml}, 1.0 \mathrm{~g} / \mathrm{ml}$ of herbal soup respectively, 3 days post vaccination. Group G was positive herbal control group. Group H was immunised control. Same as below.

2. Values in the same column with different letters show significant difference, lower case means $\mathrm{P}<0.05$, capital letters mean $\mathrm{P}<0.01$.

Table 2: Thymus indexes in different experimental groups

\begin{tabular}{lllll}
\hline \multirow{2}{*}{ groups } & \multicolumn{4}{c}{ Age (day) } \\
\cline { 2 - 5 } & 52 & 59 & 73 & 87 \\
\hline $\mathrm{A}$ & $5.26 \pm 0.35^{\mathrm{a}}$ & $5.35 \pm 0.25^{\mathrm{Aa}}$ & $5.56 \pm 0.24^{\mathrm{A}}$ & $5.72 \pm 0.16^{\mathrm{A}}$ \\
$\mathrm{B}$ & $5.32 \pm 0.48^{\mathrm{b}}$ & $5.53 \pm 0.37^{\mathrm{b}}$ & $5.58 \pm 0.31^{\mathrm{A}}$ & $5.73 \pm 0.22^{\mathrm{A}}$ \\
$\mathrm{C}$ & $5.34 \pm 0.12^{\mathrm{b}}$ & $5.62 \pm 0.41^{\mathrm{Bb}}$ & $5.92 \pm 0.28^{\mathrm{Bb}}$ & $6.12 \pm 0.43^{\mathrm{Ba}}$ \\
$\mathrm{D}$ & $5.32 \pm 0.24^{\mathrm{a}}$ & $5.54 \pm 0.28^{\mathrm{b}}$ & $5.86 \pm 0.33^{\mathrm{Bb}}$ & $5.98 \pm 0.35^{\mathrm{Bb}}$ \\
$\mathrm{E}$ & $5.30 \pm 0.42^{\mathrm{b}}$ & $5.49 \pm 0.31^{\mathrm{b}}$ & $5.77 \pm 0.24^{\mathrm{Bab}}$ & $5.86 \pm 0.29^{\mathrm{Ca}}$ \\
$\mathrm{F}$ & $5.33 \pm 0.32^{\mathrm{b}}$ & $5.61 \pm 0.28^{\mathrm{Bb}}$ & $5.90 \pm 0.18^{\mathrm{Bb}}$ & $6.07 \pm 0.49^{\mathrm{Ba}}$ \\
$\mathrm{G}$ & $5.32 \pm 0.32^{\mathrm{b}}$ & $5.53 \pm 0.43^{\mathrm{b}}$ & $5.83 \pm 0.42^{\mathrm{Bb}}$ & $5.93 \pm 0.26^{\mathrm{Ba}}$ \\
$\mathrm{H}$ & $5.28 \pm 0.25^{\mathrm{a}}$ & $5.48 \pm 0.19^{\mathrm{b}}$ & $5.74 \pm 0.36^{\mathrm{Bab}}$ & $5.82 \pm 0.40^{\mathrm{Ca}}$ \\
\hline
\end{tabular}

Note: Values in the same column with different letters show significant differences, lowercase means $\mathrm{P}<0.05$, capital letter means $\mathrm{P}<0.01$.

The spleen index was significantly higher in the high- and middle-dose groups compared with the control group, the $\mathrm{P}$ value being $<0.01$ at day 73 , day 87 of age, $\mathrm{P}<0.05$ at day 52 and day 59 of age. Significant changes were achieved at day 59 , day 73, and day 87 of age in the low-dose group $(\mathrm{P}<0.05)$, and at day 52, and day 59 in the Wen du qing group. No significant difference was observed between the herbal groups and the positive drug control. These results imply Gan lian Yu ping feng powder is equivalent to the positive herbal formula in stimulating the growth of the spleen (Table 3 ).

There are increases in the index of Bursa of Fabricius of all herbal treated groups, significantly higher than the control group. The high level of index remains from day 52 through day 87 of age, while the increase was significant at days 59, 73 and 87 in the low-dose group. The index in Wen du qing group was significantly higher than the control group at days 52 and 59 of age (Table 4$)$. 
http://dx.doi.org/10.4314/ajtcam.v10i4.12

Table 3: Spleen indexes in different experimental groups

\begin{tabular}{lllll}
\hline \multirow{2}{*}{ Groups } & \multicolumn{4}{c}{ Age (day) } \\
\cline { 2 - 5 } & 52 & 59 & 73 & 87 \\
\hline $\mathrm{A}$ & $3.09 \pm 0.34^{\mathrm{a}}$ & $3.02 \pm 0.31^{\mathrm{a}}$ & $2.60 \pm 0.25^{\mathrm{A}}$ & $2.23 \pm 0.32^{\mathrm{A}}$ \\
$\mathrm{B}$ & $3.15 \pm 0.27^{\mathrm{b}}$ & $3.10 \pm 0.24^{\mathrm{b}}$ & $2.64 \pm 0.30^{\mathrm{A}}$ & $2.25 \pm 0.28^{\mathrm{A}}$ \\
$\mathrm{C}$ & $3.18 \pm 0.16^{\mathrm{b}}$ & $3.15 \pm 0.18^{\mathrm{b}}$ & $2.82 \pm 0.15^{\mathrm{BCa}}$ & $2.58 \pm 0.31^{\mathrm{BCa}}$ \\
$\mathrm{D}$ & $3.15 \pm 0.23^{\mathrm{b}}$ & $3.13 \pm 0.23^{\mathrm{b}}$ & $2.77 \pm 0.31^{\mathrm{BCa}}$ & $2.55 \pm 0.28^{\mathrm{BCa}}$ \\
$\mathrm{E}$ & $3.11 \pm 0.18^{\mathrm{a}}$ & $3.12 \pm 0.14^{\mathrm{b}}$ & $2.72 \pm 0.28^{\mathrm{BDa}}$ & $2.49 \pm 0.37^{\mathrm{BDa}}$ \\
$\mathrm{F}$ & $3.16 \pm 0.23^{\mathrm{b}}$ & $3.14 \pm 0.19^{\mathrm{b}}$ & $2.80 \pm 0.31^{\mathrm{BCa}}$ & $2.55 \pm 0.30^{\mathrm{BCa}}$ \\
$\mathrm{G}$ & $3.14 \pm 0.22^{\mathrm{b}}$ & $3.12 \pm 0.14^{\mathrm{b}}$ & $2.75 \pm 0.24^{\mathrm{BCb}}$ & $2.50 \pm 0.27^{\mathrm{BCa}}$ \\
$\mathrm{H}$ & $3.11 \pm 0.16^{\mathrm{a}}$ & $3.10 \pm 0.31^{\mathrm{b}}$ & $2.71 \pm 0.33^{\mathrm{BDa}}$ & $2.42 \pm 0.26^{\mathrm{BDa}}$ \\
\hline
\end{tabular}

Note: Values in the same column with different letters show significant differences, lowercase means $\mathrm{P}<0.05$, capital letter means $\mathrm{P}<0.01$.

Table 4: Indices of Bursa of Fabricius in different experimental groups

\begin{tabular}{lllll}
\hline \multirow{2}{*}{ groups } & \multicolumn{4}{c}{ Age (day) } \\
\cline { 2 - 5 } & 52 & 59 & 73 & 87 \\
\hline $\mathrm{A}$ & $1.62 \pm 0.21^{\mathrm{a}}$ & $1.31 \pm 0.14^{\mathrm{a}}$ & $1.01 \pm 0.17^{\mathrm{A}}$ & $0.61 \pm 0.09^{\mathrm{A}}$ \\
$\mathrm{B}$ & $1.68 \pm 0.15^{\mathrm{b}}$ & $1.40 \pm 0.18^{\mathrm{b}}$ & $1.03 \pm 0.16^{\mathrm{A}}$ & $0.63 \pm 0.10^{\mathrm{A}}$ \\
$\mathrm{C}$ & $1.73 \pm 0.09^{\mathrm{b}}$ & $1.52 \pm 0.13^{\mathrm{b}}$ & $1.23 \pm 0.21^{\mathrm{Ba}}$ & $0.92 \pm 0.11^{\mathrm{Ba}}$ \\
$\mathrm{D}$ & $1.69 \pm 0.11^{\mathrm{b}}$ & $1.48 \pm 0.20^{\mathrm{b}}$ & $1.20 \pm 0.18^{\mathrm{Ba}}$ & $0.89 \pm 0.15^{\mathrm{Ba}}$ \\
$\mathrm{E}$ & $1.66 \pm 0.09^{\mathrm{a}}$ & $1.46 \pm 0.17^{\mathrm{b}}$ & $1.14 \pm 0.20^{\mathrm{Bb}}$ & $0.84 \pm 0.16^{\mathrm{Bb}}$ \\
$\mathrm{F}$ & $1.72 \pm 0.11^{\mathrm{b}}$ & $1.51 \pm 0.15^{\mathrm{b}}$ & $1.21 \pm 0.18^{\mathrm{Ba}}$ & $0.90 \pm 0.17^{\mathrm{Ba}}$ \\
$\mathrm{G}$ & $1.68 \pm 0.19^{\mathrm{b}}$ & $1.47 \pm 0.20^{\mathrm{b}}$ & $1.18 \pm 0.20^{\mathrm{Bb}}$ & $0.87 \pm 0.13^{\mathrm{Ba}}$ \\
$\mathrm{H}$ & $1.65 \pm 0.10^{\mathrm{a}}$ & $1.42 \pm 0.19^{\mathrm{b}}$ & $1.10 \pm 0.17^{\mathrm{Bb}}$ & $0.82 \pm 0.16^{\mathrm{Bb}}$ \\
\hline
\end{tabular}

Note: Values in the same column with different letters show significant differences, lowercase means $\mathrm{P}<0.05$, capital letter means $\mathrm{P}<0.01$.

\section{Effects of the herbals on cytokine contents in serum}

There are significant increases in the contents of IFN- $\gamma$ in all herbal groups and at all the four time points. The high levels in the high-, middle- and low-dose groups remain the same from day 52 through day 87 of age. There are increases in the Wen du qing group at days 52 and 59 of age $(\mathrm{P}<0.05)$ when compared with the control (Table 5).

Table 5: IFN- $\gamma$ contents in different experimental groups

\begin{tabular}{lllll}
\hline \multirow{2}{*}{ Groups } & \multicolumn{4}{c}{ Age (day) } \\
\cline { 2 - 5 } & 52 & 59 & 73 & 87 \\
\hline $\mathrm{A}$ & $5.04 \pm 0.011^{\mathrm{a}}$ & $5.26 \pm 0.006^{\mathrm{a}}$ & $5.42 \pm 0.006^{\mathrm{A}}$ & $5.35 \pm 0.025^{\mathrm{A}}$ \\
$\mathrm{B}$ & $5.09 \pm 0.007^{\mathrm{b}}$ & $5.35 \pm 0.008^{\mathrm{b}}$ & $5.45 \pm 0.012^{\mathrm{A}}$ & $5.36 \pm 0.031^{\mathrm{A}}$ \\
$\mathrm{C}$ & $5.26 \pm 0.089^{\mathrm{b}}$ & $5.46 \pm 0.011^{\mathrm{b}}$ & $5.74 \pm 0.013^{\mathrm{Ba}}$ & $5.74 \pm 0.021^{\mathrm{Ba}}$ \\
$\mathrm{D}$ & $5.13 \pm 0.010^{\mathrm{b}}$ & $5.40 \pm 0.007^{\mathrm{b}}$ & $5.68 \pm 0.018^{\mathrm{Ba}}$ & $5.65 \pm 0.019^{\mathrm{Ba}}$ \\
$\mathrm{E}$ & $5.11 \pm 0.011^{\mathrm{b}}$ & $5.34 \pm 0.015^{\mathrm{b}}$ & $5.56 \pm 0.016^{\mathrm{Bb}}$ & $5.55 \pm 0.009^{\mathrm{Bb}}$ \\
$\mathrm{F}$ & $5.27 \pm 0.092^{\mathrm{b}}$ & $5.46 \pm 0.012^{\mathrm{b}}$ & $5.72 \pm 0.023^{\mathrm{Ba}}$ & $5.71 \pm 0.038^{\mathrm{Ba}}$ \\
$\mathrm{G}$ & $5.17 \pm 0.012^{\mathrm{b}}$ & $5.39 \pm 0.031^{\mathrm{b}}$ & $5.66 \pm 0.013^{\mathrm{Bb}}$ & $5.64 \pm 0.007^{\mathrm{Bb}}$ \\
$\mathrm{H}$ & $5.12 \pm 0.086^{\mathrm{b}}$ & $5.35 \pm 0.010^{\mathrm{b}}$ & $5.56 \pm 0.012^{\mathrm{Ba}}$ & $5.48 \pm 0.019^{\mathrm{Bb}}$ \\
\hline
\end{tabular}

Note: Values in the same column with different letters show significant differences, lowercase means $\mathrm{P}<0.05$, majuscule means $\mathrm{P}<0.01$. 
http://dx.doi.org/10.4314/ajtcam.v10i4.12

There are significant reductions in the contents of IL-4 in all the herbal treated groups compared with the control. The low levels in the high-, middle-, and low-dose groups remain the same from day 52 through day 87 of age. There are differences in the wen du qing group at days 52 and 59 of age $(\mathrm{P}<0.05)$ in comparison with the control group (Table 6).

Table 6: IL-4 contents in different experimental groups

\begin{tabular}{lllll}
\hline \multirow{2}{*}{ Groups } & \multicolumn{4}{c}{ Age (day) } \\
\cline { 2 - 5 } & 52 & 59 & 73 & 87 \\
\hline $\mathrm{A}$ & $5.45 \pm 0.025^{\mathrm{a}}$ & $5.38 \pm 0.023^{\mathrm{a}}$ & $5.16 \pm 0.009^{\mathrm{A}}$ & $4.91 \pm 0.021^{\mathrm{A}}$ \\
$\mathrm{B}$ & $5.36 \pm 0.023^{\mathrm{b}}$ & $5.32 \pm 0.018^{\mathrm{b}}$ & $5.13 \pm 0.016^{\mathrm{A}}$ & $4.88 \pm 0.016^{\mathrm{A}}$ \\
$\mathrm{C}$ & $5.12 \pm 0.010^{\mathrm{b}}$ & $4.96 \pm 0.035^{\mathrm{b}}$ & $4.68 \pm 0.024^{\mathrm{Ba}}$ & $4.40 \pm 0.003^{\mathrm{Ba}}$ \\
$\mathrm{D}$ & $5.27 \pm 0.023^{\mathrm{b}}$ & $5.10 \pm 0.028^{\mathrm{b}}$ & $4.79 \pm 0.038^{\mathrm{Bb}}$ & $4.49 \pm 0.013^{\mathrm{Bb}}$ \\
$\mathrm{E}$ & $5.35 \pm 0.021^{\mathrm{b}}$ & $5.21 \pm 0.016^{\mathrm{b}}$ & $4.88 \pm 0.026^{\mathrm{Bc}}$ & $4.54 \pm 0.032^{\mathrm{Bc}}$ \\
$\mathrm{F}$ & $5.14 \pm 0.008^{\mathrm{b}}$ & $5.00 \pm 0.024^{\mathrm{b}}$ & $4.72 \pm 0.034^{\mathrm{Ba}}$ & $4.43 \pm 0.009^{\mathrm{Ba}}$ \\
$\mathrm{G}$ & $5.29 \pm 0.035^{\mathrm{b}}$ & $5.13 \pm 0.032^{\mathrm{b}}$ & $4.81 \pm 0.021^{\mathrm{Bb}}$ & $4.52 \pm 0.028^{\mathrm{Bb}}$ \\
$\mathrm{H}$ & $5.37 \pm 0.027^{\mathrm{b}}$ & $5.22 \pm 0.021^{\mathrm{b}}$ & $4.95 \pm 0.032^{\mathrm{Bc}}$ & $4.58 \pm 0.036^{\mathrm{Bc}}$ \\
\hline
\end{tabular}

Note: Values in the same column with different letters show significant differences, lowercase means $\mathrm{P}<0.05$, majuscule means $\mathrm{P}<0.01$.

\section{Discussion}

The level of antibody titers is an index for humoral immunity. Humoral immunity is a very important specific immunological response mediated by B cells. It plays a vital role in combating the infectious factors and is the first step to defend the invasion of exogenous pathogens and to eradicate and inactivate pathogenic organisms. The antibodies produced by $\mathrm{B}$ cells will trap to or catch the pathogens directly for the antibody-antigen complex, which will be recognised, engulfed and eradicated by macrophages. In the present study, the antibody titers to ILT vaccine was significantly elevated in chicks treated with Gan lian Yu ping feng powder, indicating this formula possesses humoral immuno-enhancing properties.

The immune organs are those structures carrying on immunological functions in poultry and mammalian animals. The developing status of the immune organs directly affects the potentials of the body to respond and combat the infection and invasion of pathogenic organisms. The important immune organs in poultry defence systems include the thymus, the spleen, and the Bursa of Fabricius. Rivas and Fabricant (1988) reported that the weights of thymus, spleen, and Bursa of Fabricius can be used as indexes to evaluate the immunological status in chicks. The increase in relative or absolute weights of these organs indicates increases in both cellular and humoral immunity. Use of Gan lian Yu ping feng powder elevated the indexes of immune organs significantly compared with the controls (Tables $2,3,4$ ) in the present study, indicating that the herbal formula promotes the development of the thymus, spleen, and Bursa of Fabricius in chicks.

IFN- $\gamma$ and IL-4 are the typical cytokines presenting Th1 or Th2 cellular immune responses ( $\mathrm{Li}$ et al, 2002). Interferon is a kind of cytokine possessing various modulating functions and plays crucial role in immuno-modulating Th1 and Th2

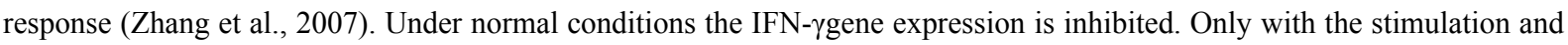
induction of certain factors is the expression of IFN- $\gamma$ gene activated and starts to transcript and express itself. Virus, bacteria and certain herbals will stimulate the expression of IFN- $\gamma$ genes. The IFN- $\gamma$ gene is released from inhibition when virus or herbals contact the cell membranes; mRNA is synthesised and IFN- $\gamma$ is released outside the cells. High level of IFN- $\gamma$ indicates active Th1 cell activities and activated cyto-immunity (Wen et al., 2008). In addition, IFN- $\gamma$ is a typical cytokine secreted by Th1 cells, and at the same time it is an indicator of cell-mediated immunity (Huang et al., 2003). IL-4 is a typical cytokine secreted by Th2 cells. Enhancement of IL-4 contents will result in the imbalance of Th1/Th2, leading eventually to Th1 or Th2 type diseases (Wu et al., 2001). In our present study, Gan lian Yu ping feng powder significantly elevated the 
http://dx.doi.org/10.4314/ajtcam.v10i4.12

IFN- $\gamma$ content and decreased IL-4 level. At the same time the herbal induced a Th1 response, and brought the Th2 biased response to a normal Th1/Th2 balance (Hopfenspirger et al., 2001).

Yu Ping Feng San (San means powder) was described in the Song Dynasty of the 10th Century in Shi Yi De Xiao Fang, an ancient TCM (traditional Chinese medicine) textbook. In TCM, Yu Ping Feng San is believed to be a Qi nourishing (defence-enhancing) formula. Recently there have been reports on the immuno-modulatory effects of Yu Ping Feng San (Tang and Jiang, 2011; Wang and Yang, 2010). The T-lymphocyte CD4/CD8 ratio increased significantly after the intake of Yu Ping Feng San. This increase was likely due to the TCM intake (Poon et al., 2006). Yu Ping Feng San elevated the antibody titers to bird flu vaccination in quills (Gu et al., 2009), and lymphocyte proliferation in vitro in chickens (Lin et al., 2009).

In our study, the traditional herbal formula Yu Ping Feng San when modified with the addition of Gan cao to replenish spleen Qi and Chuan xin lian to clear the heat evil (anti-virus) elevated the immunity of birds. Of the three dosages used, the high and middle doses showed better results. This study will be used as a reference in the study of developing good quality and highly effective herbal immuno-enhancers.

\section{Acknowledgements}

This study was financially supported by the Ministry of Science and Technology, China (Project No. 2011BAD34B02).

\section{References}

1. Cheng JJ, Li QY, WY, Zhong XH. Effects of Huangqi Maxingshigan decoction on infectious laryngotracheitis in chickens. Italian Journal of Animal Science 2011; 10(2): 124-130.

2. Gu XG, Wang WJ, Hu SH. Influence of Yu Ping Feng San on bird flu vaccination in quills. Journal of Traditional Chinese Veterinary Medicine, 2009, 28(4):57-60

3. Hopfenspirger MT, Parr SK, Hopp RJ, Townley RG, Agrawal DK. Mycobacterial Antigens Attenuate Later Phase Response, Airway Hyperresponsiveness, and Bronchoalveolar Lavage Eosinophilia in a Mouse Model of Bronchial Asthma. Int Immunopharamacol. 2001; 1(9): 1743-1751.

4. Huang JL, Long ZJ, Wu HQ et al. Effect of Linggui Zhugan soup on T-lymphocyte subsets IL-2 activity of immunosuppressive mice models. Journal of Chinese experimental formulas. 2003;9(6):35-40.

5. Li CQ, Xu YJ, Zhong XN, et al. Cytological Changes in Bronchoalveolar Lavage during various Th1/Th2 responses. Journal of Cell and molecular immunology. 2002;18(6):575-577,585.

6. Lin LH, Zheng Y, Zhong WP, He YQ. Effects of Yu ping Feng san on spleen lymphocyte proliferation in chickens. Fujian Journal of Animal Science and Veterinary Medicine. 2009, 31(4):1-2

7. Liu PF, Shi WY, Zhao YT, Zhong XH. Effects of Chinese herbal formula Maxing Shigan powder on IgA secreting cells in chicken bronchus. Journal of Medicinal Plants Research. 5(17):4304-4309. 2011

8. Malik F, Kumar A, Bhushan S, Mondhe DM, Pal HC, Sharma R, Khajuria A, Singh S, Singh G, Saxena AK, Suri KA, Qazi GN, Singh J. Immune modulation and apoptosis induction: Two sides of antitumoural activity of a standardised herbal formulation of Withania somnifera. Eur J Cancer, 2009, 45(8): 1494-1509.

9. Poon PM, Wong CK, Fung KP, Fong CY, Wong EL, Lau JT, Leung PC, Tsui SK, Wan DC, Waye MM, Au SW, Lau CB, Lam CW. Immunomodulatory Effects of a Traditional Chinese Medicine with Potential Antiviral Activity: A Self-Control Study. The American Journal of Chinese Medicine. 2006; 34(1): 13-21

10. Ren CL, Wang P, Yang YH. Application of herbal immunoenhancers in poultry industry. Poultry and disease control, 2007,(10):30-34. 

http://dx.doi.org/10.4314/ajtcam.v10i4.12

11. Rivas A L, Fabricant J. Indications of immunodepression in chickens infected with various strains of Marek's disease virus. Avian Diseases, 1988, 32(1): 1-8.

12. Sun ZG., Li JM, Xu YH, Zhang MF, 2006. The study of Infectious laryngotracheitis virus vaccine. China Anim. Husb. Vet. Med. 33:41-44.

13. Tang Y, Jiang GR (2011). Advance in empirical study of the immune enhancement of the different extract of Yupingfeng Powder. Anhui Medical and Pharmaceutical Journal. 15( 2): 141-143.

14. Wang CG, Zhang T, Zhong XH, Zhao ZJ. Effects of modified pulsatilla decoction on avian colibacillosis and concentrations of nitrogen oxide (NO) and tumor necrosis factor- $\alpha(\mathrm{TNF}-\alpha)$ in serum. Journal of Medicinal Plants Research. Vol. 6(2):220-224, 2012

15. Wang FC, Yan YB, Zhang YH, Han YC, Guan C. Effects of immune synergist of Chinese medicinal herbs on the efficacy of vaccination against classic swine fever. African Journal of Biotechnology Vol. 11(6), pp. 1535-1539, 2012

16. Wang FC, Fang CG, Zhang YH, Wang HB, Han YC (2006). Effects of Compound Chinese Herbal Immune Synergist on Immunity of Egg laying Chicken. Acta Veterinaria et Zootechnica Sinica. 37(2): 187-192.

17. Wang H, Li FL, Si MX et al. Influence of compound herbals on performance and immuno-index in huainan maji chickens. Modern Agricultural Technology. 2008;(8):173-176.

18. Wang QJ, Yang JS. Influence of Yu ping feng powder on animal immunity and clinical application. Siliao Bo lan, 2010,1:39-41

19. Wen Q, Meng Q, Wu ZG. Expression and significance of IFN- $\gamma$, IL-4, IL-10 in serum of kawasaki disease patients. Chinese Practical Medicine. 2008;3(23):62-63.

20. $\mathrm{Wu} \mathrm{J}, \mathrm{Xu}$ J, Zhong NS. BCG and Thl/Th2 balance in allergic asthma. Foreign medicine: Volume of respiratory system. 2001;21(3):151-153,156.

21. Xu YG, Ma R, Yang XH, Tang XD, Sun SZ (2010). Effect of Yiqi Bushen Granule on the peripheral natural killer cell and $\gamma \delta$ T-cell in the patients with minimal residual leukemia. Chin J. Integr. Med. 16(5): 417-421.

22. Xu Z, Chen X, Zhong Z, Chen L, Wang Y (2011). Ganoderma lucidum polysaccharides: immunomodulation and potential anti-tumor activities. Am. J. Chin Med. 39(1): 15-27.

23. Zhang DX, Shi WY, Zhao YT, Zhong XH. Adjuvent effects of Sijunzi decoction in chickens orally vaccinated with attenuated Newcastle disease vaccine. Afr J Tradit Complement Altern Med. 2012,9(1):120 130.

24. Zhang W, Zhu LQ, Ma FL et al. Research advances in IFN- $\gamma$ in chickens. Journal of animal science and veterinary medicine. 2007;26(2):43-46. 